\title{
Differential Response to Moderate UV-B Irradiation of Two Heterocystous Cyanobacteria Isolated from a Temperate Ricefield
}

\author{
Germán Pérez, Soledad Doldán, Omar Borsani, Pilar Irisarri \\ Departamento Biología Vegetal, Facultad de Agronomía, Universidad de la República, Montevideo, Uruguay \\ Email: irisarri@fagro.edu.uy
}

Received December 15, 2011; revised January 4, 2012; accepted January 15, 2012

\begin{abstract}
In cyanobacteria both photosynthesis and nitrogen fixation can be affected by UV radiation. Two of the most abundant heterocystous cyanobacteria isolates from a temperate ricefield in Uruguay belonging to Anabaena and Calothrix genus were exposed for 1 or 3 hours to UV-B dosis similar to those to which they are exposed in summer. Anabaena survival after $1 \mathrm{~h}$ of UV-B exposure was $10 \%$ whereas in Calothrix's was $30 \%$. Both the quantum yields of photosybtem II fluorescence and $\mathrm{O}_{2}$ photoevolution decreased with time of UV-B exposure for Calothrix and only till $1 \mathrm{~h}$ for Anabaena. Only the Calothrix strain presented phycoerithryn as antenna pigment and constitutive UV-B screening mycosporine like aminoacids. In the Anabaena strain, nitrogenase activity was drastically reduced with UV-B irradiation but in $\mathrm{Ca}$ lothrix was not affected. Proline content and lipid peroxidation increased after 3 hours of UV-B exposure only in Anabaena sp. The antioxidant enzyme activities evaluated followed different trends for both isolates, with an increase in superoxide dismutase activity in the Calothrix isolate. These results show that the two nitrogen-fixing cyanobacteria studied have different responses to UV-B radiation and that cyanobacteria diversity may be considered when selecting strains to be used as biofertilizers.
\end{abstract}

Keywords: Cyanobacteria; Antioxidant Responses to UV-B; Mycosporine; Nitrogenase Activity

\section{Introduction}

The current trend in the decrease of stratospheric ozone from anthropogenic inputs of chlorinated fluorocarbons has caused an increase of ultraviolet-B radiation (UV-B, $290-320 \mathrm{~nm}$ ) reaching the biosphere. Site-specific ozone reductions have been reported over South America as far as $30^{\circ} \mathrm{S}$ as a consequence of the transport of air masses with low ozone concentrations after the break-up of Antarctic vortex circulation [1]. High doses of UV-A/B radiation can also pass through the water column and have deleterious effects on aquatic systems [2]. UV-B radiation is the one that produces the most severe cellular damage due to its direct effects on DNA and proteins and indirectly by the reactive oxygen species (ROS) production [3]. The damage, however, is dependant of the irradiance/dose received by the cells.

Cyanobacteria comprise the biggest and most widely distributed group of photosynthetic prokaryotes. They absorb solar radiation to drive photosynthesis and nitrogen fixation in some cases, being exposed to high doses of UV radiation. The main biochemical and physiological processes altered by UV radiation in these bacteria are surviving rates, pigmentation, motility, $\mathrm{O}_{2}$ photoevo- lution, $\mathrm{CO}_{2}$ and $\mathrm{N}_{2}$ fixation, and the phycolibiprotein content. Many cyanobacteria have developed mechanisms to prevent the toxic effects caused by UV. Among these, DNA damage repair mechanisms, accumulation of detoxifying and antioxidant enzymes or synthesis of UVprotectants compounds [4].

Among the nitrogen fixing cyanobacteria, the heterocystous forming ones seem to be the most abundant in the water column and on the surface of rice paddy fields [5]. The fact that heterocystous forming cyanobacteria can assimilate $\mathrm{CO}_{2}$ and fix $\mathrm{N}_{2}$, make them suitable to be used as biofertilizers [6]. A rice inoculation assay using heterocystous-cyanobacteria in Uruguay was not successful [7], suggesting that conditions to improve inoculant survival must be studied. The inoculant was applied at flooding stage and so cyanobacteria received levels of UV radiation similar to those reported at the same latitude for shallow lagoons in Uruguay [8]. Light is the most variable of the resources essential for photosynthesis in aquatic environments varying with greatest amplitude on short time scales from effects of vertical mixing, cloud cover, and the diel cycle of sunlight. Thus, individual cells must cope with a wide variability in light on 
time scales shorter than their lifetime [9].

Under the hypothesis that diverse cyanobacteria isolated from the same site may cope with UV radiation in a different form, the aim of this work was to study the UV-B response at laboratory conditions of two of the most abundant cyanobacterial isolates from a temperate rice paddy field [10] at dosis to which they are normally exposed. Estimation of growth, their physiological status and some of their UV-protective mechanisms were studied.

\section{Materials and Methods}

\subsection{Organisms and Growth Conditions}

The filamentous heterocystous cyanobacteria Calothrix sp. BI22 and Anabaena sp. BI42 were isolated from Uruguayan rice paddy fields [10]. The cultures were axenically grown in nitrogen free BG 11 medium [11] buffered with $10 \mathrm{mM}$ HEPES, $\mathrm{pH} 7.6$ at $25^{\circ} \mathrm{C} \pm 2{ }^{\circ} \mathrm{C}$ with white light supplied by fluorescent lamps providing a photosynthetic photon flux density of $50 \mu \mathrm{E} \cdot \mathrm{m}^{-2} \cdot \mathrm{s}^{-1}$. Exponentially growing cultures were used for the different experiments. Cultures were sampled under sterile conditions after homogenization with a Potter pestle and biomass was estimated as dry weight. Unless otherwise stated, cultures with an initial dry weight of about 3 $\mathrm{mg} \cdot \mathrm{mL}^{-1}$ were used in all experiments.

\subsection{UV Treatment}

A well homogenised culture suspension of each cyanobacterium was poured into open Petri dishes (diameter 22 $\mathrm{cm})$. The cultures were exposed directly and only to artificial UV-B $\left(0.034 \mathrm{~mW} \cdot \mathrm{cm}^{-2}\right)$ and UV-A $\left(15.54 \mu \mathrm{W} \cdot \mathrm{cm}^{-2}\right)$ during $1 \mathrm{~h}$ and $3 \mathrm{~h}$ with constant shaking to avoid selfshading. UV-B irradiation was provided by a Hi-Tech lamp G25T8E, Japan. The irradiance of the light source was determined with an IL1400A radiometer/photometer (International Light Inc.) equipped with UVAR and UVBR sensors.

\subsection{Survival}

The survival of the irradiated and control organisms was studied on agar plates. After irradiating the cultures, aliquots of $100 \mu \mathrm{L}$ were diluted to $1 \mathrm{~mL}$ with BG11 medium and transferred to nitrogen free BG11 sterile solid plates and grown in the same conditions described above. After 10 days of incubation, colonies were counted under a binocular microscope and the survival was calculated by the colony numbers of test samples $(\mathrm{Nt})$ divided by the control samples $(\mathrm{Nc})($ survival $\%=\mathrm{Nt} / \mathrm{Nc} \times 100)$.

\subsection{Absorption Spectra}

Culture suspensions were homogenized in a Potter pestle and then immobilized in agarose $1 \%(\mathrm{w} / \mathrm{v})$ in a $3 \mathrm{~mL}$-quartz cuvette. A scanning spectrum $(300-750 \mathrm{~nm})$ of immobilized cells exposed for different periods of time to the beam of the spectrophotometer at $280 \mathrm{~nm}$ was obtained, according to [12].

Phycobiliproteins were extracted according to [13].

\subsection{Fluorescence Emission Spectrum}

The emission spectrum was measured with a spectrofluorophotometer (RF-1501, Shimadzu) at room temperature with an excitation wavelength of $445 \mathrm{~nm}$ and emission wavelength between 600 and $780 \mathrm{~nm}$.

\subsection{Chlorophyll Fluorescence Parameters}

The in vivo chlorophyll $a$ fluorescence from both cyanobacteria cultures was measured with a FMSI fluorometer (Hansatech Instrument Ltd., King's Lynn, UK) using saturating actinic light $\left(8000 \mu \mathrm{mol} \cdot \mathrm{m}^{-2} \cdot \mathrm{s}^{-1}\right.$ for $8 \mathrm{~s}$ as described by [14]. Prior to the measurement the cyanobacteria were adapted $30 \mathrm{~min}$ to darkness. Fluorescence parameters were calculated as described by [15].

\subsection{Photosynthetic Oxygen Evolution}

Photosynthesis was measured as $\mathrm{O}_{2}$ evolution with a Clark-type $\mathrm{O}_{2}$ electrode (Hansatech Instruments Ltd.) as described in [10]. Two $\mathrm{mL}$ aliquots of cell suspensions which were exposed to UV treatments were placed in a $27^{\circ} \mathrm{C}$ controlled cuvette and illuminated with a quantum flux density of $400 \mu \mathrm{E} \cdot \mathrm{m}^{-2} \cdot \mathrm{s}^{-1}$.

\subsection{Extraction and Analysis of Mycosporine-Like Aminoacids (MAA)}

Cells were harvested by centrifugation at $8000 \mathrm{~g}$ for 5 min at room temperature. Pellets were first incubated with methanol $20 \%(\mathrm{v} / \mathrm{v})$ at $45^{\circ} \mathrm{C}$ for $2.5 \mathrm{~h}$ and then centrifuged $(6000 \mathrm{~g} ; 5 \mathrm{~min})$ at $6^{\circ} \mathrm{C}-8^{\circ} \mathrm{C}$. The process was repeated twice. The extracts were cleared using nitrocellulose membranes $(0.45 \mu \mathrm{m})$ and characterized using a HPLC system (Shimadzu SPD-10A UV-VIS detector. Kyoto, Japan) equipped with a LiChrosorb RP-18 column. The wavelength for detection was $330 \mathrm{~nm}$ at a flow rate of $1.0 \mathrm{~mL} / \mathrm{min}$ at $25^{\circ} \mathrm{C}$ and a mobile phase of $0.2 \%$ acetic acid. The separated aminoacids were detected at $330 \mathrm{~nm}$ with a photodiode array [16]. Identification of MAAs was done by comparing the absorption spectra and retention times with standards such as Corallina officinalis (shinorine and palythine) and Porphyra sp. (porphyra-334 and shinorine). These standards were kindly provided by Dr. D.-P. Häder from the Alexander Universität (Erlangen, Germany). The database used for identification of the MAAs was http://www.biologie.unierlangen.de/botanik1/index.html. 


\subsection{Nitrogenase Activity}

To determine the response of nitrogenase activity to the exposure to UV light, an acetylene reduction assay (ARA) was performed in $10 \mathrm{~mL}$ aliquots of cell suspensions, placed in $22 \mathrm{~mL}$ vials after 1 and 3 hours of UV exposition. The incubation time with $10 \%$ acetylene in air was $45 \mathrm{~min}$ [10]. Ethylene formation was followed with a HP 5890 gas chromatograph equipped with a Porapack N column. Nitrogenase activity was expressed as $\mu$ mol ethylene $\mathrm{mg}^{-1}$ dry weight $\cdot \mathrm{h}^{-1}$.

\subsection{Lipid Peroxidation}

The formation of malondialdehyde (MDA) was used as indicator of lipid peroxidation. The determination of MDA by the thiobarbituric acid reactive substances (TBARS) method was performed as described by [17] at $532 \mathrm{~nm}$ absorbance. Lipid peroxidation was expressed as nmoles of MDA per milligram dry weight using an extinction coefficient of $156 \mathrm{mM}^{-1} \cdot \mathrm{cm}^{-1}[18]$.

\subsection{Proline Content}

Proline was extracted and quantified according to [19].

\subsection{Antioxidant Enzymatic Activities}

Superoxide dismutase (SOD) activity was assayed spectrophotometrically by monitoring inhibition of xanthine oxidase (XO; 1.1.3.22)-dependent reduction of $10 \mu \mathrm{M}$ ferricytochrome $c$ [20]. The reaction was monitored at $550 \mathrm{~nm}$ in $50 \mathrm{mM}$ potassium phosphate, $100 \mu \mathrm{M}$ EDTA, and $50 \mu \mathrm{M}$ xanthine, $\mathrm{pH}$ 7.8. One unit of SOD was defined as the activity that could inhibit the XO-dependent reduction of ferricytochrome $c$ by $50 \%$, measured as inhibition of the rate of increase in absorbance at $550 \mathrm{~nm}$ compared with a control rate, established using sufficient XO. Ferricytochrome $c$ reduction of $0.025 \mathrm{~A} 550 / \mathrm{min}$ was done at $25^{\circ} \mathrm{C}$.

Catalase (CAT) activity was determined essentially as described by [21] by measuring the decline in levels of hydrogen peroxide spectrophotometrically at $240 \mathrm{~nm}$. One unit was defined as the activity that decomposed one micromole of hydrogen peroxide per minute at $25^{\circ} \mathrm{C}$ at pH 7.0.

Ascorbate peroxidise (APX) activity was followed by decrease in absorption at $290 \mathrm{~nm}$ for 3 min (extinction coefficient $2.8 \mathrm{mM} \cdot \mathrm{cm}^{-1}$ ). The reaction mixture contained phosphate buffer $100 \mathrm{mM}(\mathrm{pH} 7.5)$, ascorbate 0.5 $\mathrm{mM}$ and $\mathrm{H}_{2} \mathrm{O}_{2} 0.2 \mathrm{mM}$ [22].

For protein quantification cultures were centrifuged (6000 $\mathrm{g}$ for $10 \mathrm{~min}$ ) and pellets were resuspended in an extraction buffer (100 mM Tris; $50 \mathrm{mM}$ EDTA; $\mathrm{NaCl}$ $100 \mathrm{mM}$; PMSF $1 \% \mathrm{fc} ; \mathrm{pH} 8$ ). The protein extract was quantified according to [23] and kept at $-80^{\circ} \mathrm{C}$ until further processing.

\subsection{SOD Detection}

SOD isozymes were analyzed on a non-denaturing polyacrilamide gel, using in-gel activity assays and with isozyme-specific inhibitors previously described by [24], and using $40 \mu \mathrm{g}$ of protein in a given analysis [25].

\subsection{Statistical Analysis}

Analysis of variance and a t-test were used to establish differences among the different radiation treatments and strains ( $\mathrm{n}=3$ or 4$)$. All experiments described were conducted independently at least twice. A confidence level of $95 \%$ was used in all analysis.

\section{Results}

\subsection{Cyanobacterial Survival to UV-B}

Growth responses of the two tested cyanobacteria Anabaena sp. BI42 and Calothrix sp. BI22 after UV-B radiation were inhibited in a different trend. Anabaena BI42 sp. showed after an hour of exposure a decrease of its survival of near $90 \%$ and reached almost a $100 \%$ after 3 hours of exposure. On the other hand, the survival decrease of Calothrix sp. BI22 was near 50\% in the first hour of irradiation and reached a $70 \%$ after 3 hours of exposure (Figure 1).

\subsection{Spectral Properties of Photosynthetic Pigments}

The absorption spectrum of photosynthetic pigments in

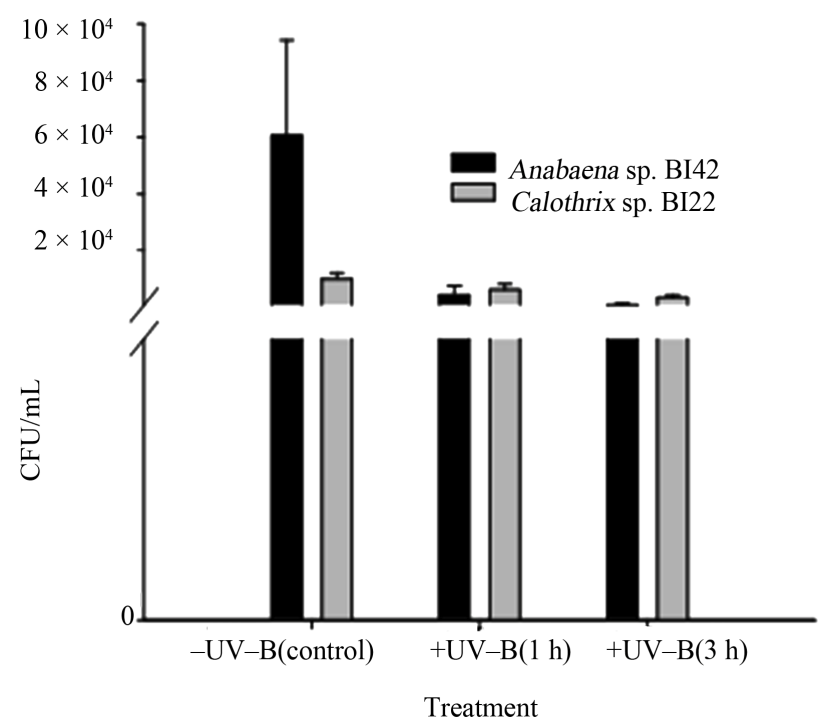

Figure 1. Growth of cyanobacteria after different times of exposure to UV-B. 
response to moderate UV-B stress (Figure 2) showed that maximum light was absorbed in two distinct regions i.e. from wavelength $400-500 \mathrm{~nm}$ and 600 to $700 \mathrm{~nm}$. In Anabaena sp. BI42 the spectrum showed absorption maxima at 683, 630, 501 and $443 \mathrm{~nm}$, corresponding to the photosynthetic pigments Chl $a$ (red peak), phycocyanin, caroten and Chl a (Soret band) respectively. The absorption maxima for Calothrix sp. BI22 corresponded to $681,629,572,503$ and $403 \mathrm{~nm}$ with an additional phycoerythrin peak. In both cyanobacteria, the absorption of light decreased in both regions with the increase in time of UV-B exposure from the beam of the spectrophotometer (Figures 2(a) and (b)). In the case of Anabaena, carotenoids that were the more affected pigments, presented a higher decrease in absorbance with exposure time to UV-B radiation than in Calothrix.

The fluorescence emission spectra of Anabaena sp. BI42 and Calothrix sp. BI22 and are shown in Figures 3(a) and (b) respectively, after different times of exposure to UV-B irradiation. The fluorescence emission peak at 670 $\mathrm{nm}$, monitored at an excitation wavelength of $445 \mathrm{~nm}$ increased with duration of UV-B irradiation for both cyanobacteria isolates. There was no shift in the peaks observed but an increase in their value due to exposure UV-B.

\subsection{Chlorophyll $a$ Fluorescence and $\mathrm{O}_{2}$ Photoevolution}

The optimum quantum yield of PSII (Fv/Fm) of the control (before exposure treatment) already showed a significant difference in the photosynthetic capacity between the two isolates $(\mathrm{p}<0.01)$. Photosynthetic efficiency was higher in Calothrix sp. BI22 (0.453 \pm 0.017$)$ than in Anabaena BI42 sp. $(0.223 \pm 0.015)$.

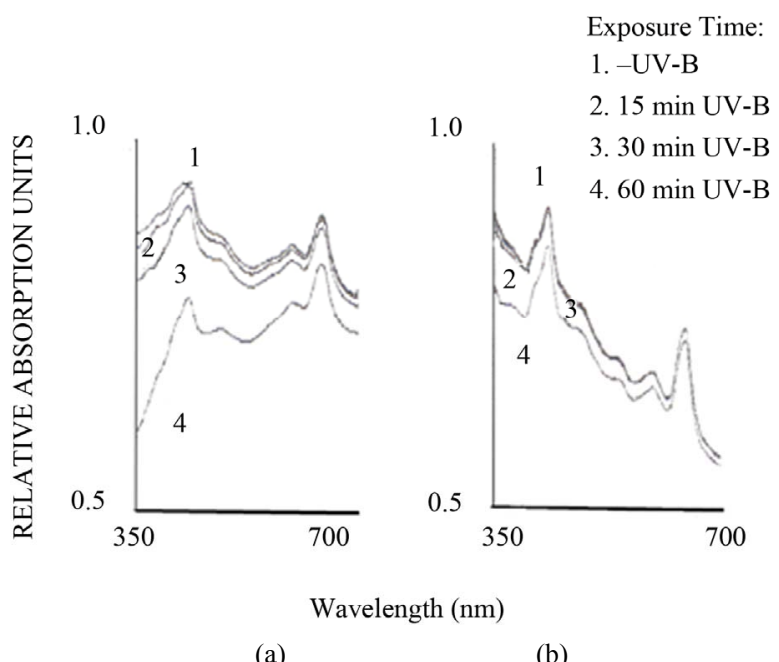

(a)

(b)

Figure 2. Absorption spectra of cells of Anabaena sp. BI42 and Calothrix sp. BI22, (a) and (b) respectively, obtained after different time of exposure to the $280 \mathrm{~nm}$ beam of the spectrophotometer.

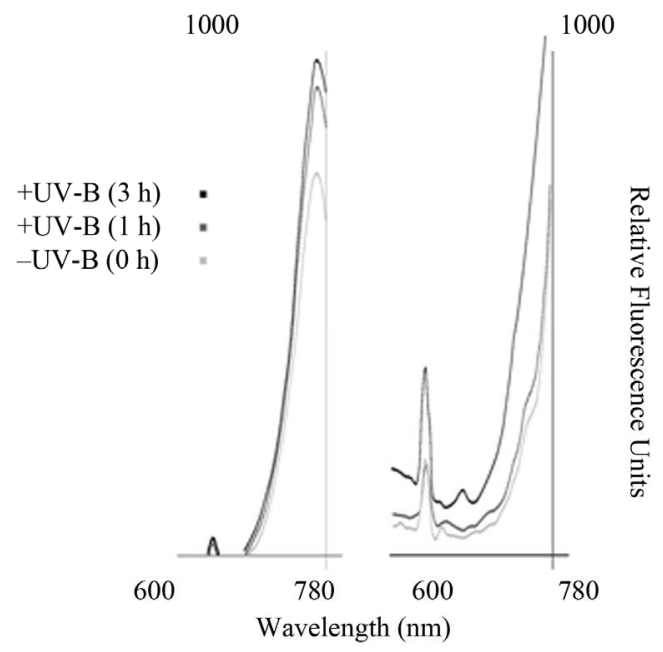

(a)

(b)

Figure 3. Impact of UV-B on emission fluorescence spectra of Anabaena sp. BI42 and Calothrix sp. BI22, (a) and (b) respectively. Cells were excited at $445 \mathrm{~nm}$ after exposure to UV-B for 0,1 and $3 \mathrm{~h}$.

Fm/Fv significantly decreased $(p<0.05)$ with the time of exposure in Calothrix sp. BI22 to UV-B (Figure 4). There was a decline of $32 \%$ of the quantum yield of PSII after 3 hours of exposure. While in Anabaena the decrease was only significantly different in the first hour ( $p$ $<0.05)$. The Fv/Fm in Anabaena reached the same value as the control sample when exposed to 3 hours to UV radiation.

The $\mathrm{O}_{2}$ photoevolution was more drastically reduced in Calothrix BI22 sp. than in Anabaena BI42 sp. (Figure 4).

\subsection{Mycosporine Like Aminoacids}

The HPLC analysis revealed the presence of two MAAs in Calothrix sp. BI22 (Figure 5). According to [26] these MAAs could be palythinol and mycosporine-2-glycine. Their retention times were 3.54 and 10.29 min espectively and their absorption maxima were 330 and $332 \mathrm{~nm}$ respectively. The content of these MAAs, 3.7 and 0.5 $\mathrm{nmol} \cdot \mathrm{g} \cdot \mathrm{DW}^{-1}$ respectively did not increase significantly with UV-B exposure. Instead, neither any peak nor an induction of any MAAs was observed in Anabaena sp. BI42 (Figure 5).

\subsection{Nitrogenase Activity}

Rates of nitrogen fixation (Table 1), measured as nitrogenase activity, were not significantly altered in Calothrix sp. BI22 due to UV-B radiation. Instead, Anabaena sp. BI42 showed a significant reduction at the very first hour of exposure $(\mathrm{p}<0.05)$ which represents a $55 \%$ decline in the nitrogen fixation of this strain. When the culture of Anabaena sp. BI42 was irradiated for 3 hours, the nitrogenase activity drastically decreases (Table 1). 


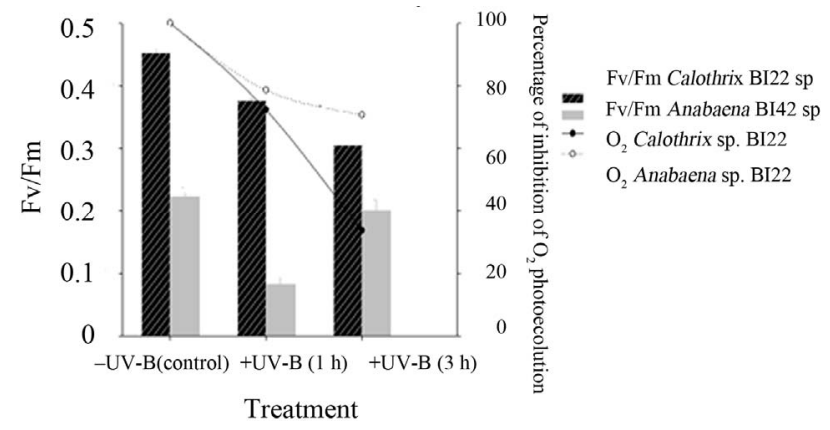

Figure 4. Photosynthetic parameters measured for both isolates Calothrix sp. BI22 and Anabaena sp. BI42 in the control or irradiated with UV-B for 1 or $3 \mathrm{~h}$. The maximum photochemical efficiency of PSII reaction centers measured as the ratio $\mathrm{FV} / \mathrm{Fm}$ and percentage of inhibition of $\mathrm{O}_{2}$ photoevolution after exposure for different times to UV-B. Results of FV/FM are reported as mean of three replicates \pm standard error. (a)

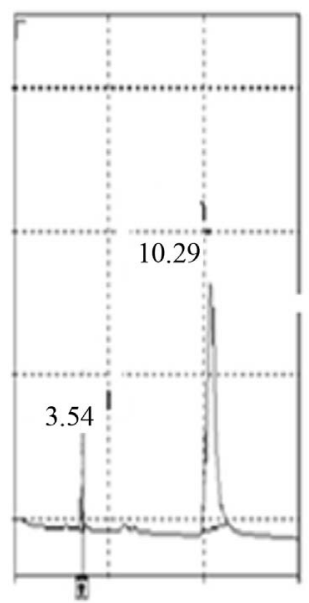

Retention Time (min) (b1) RT:3.54 min

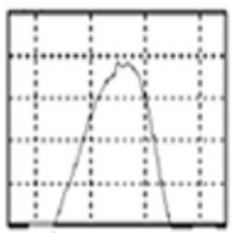

(b2) RT: $10.29 \mathrm{~min}$

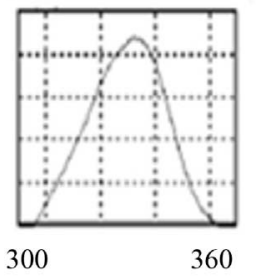

Wavelength (nm)
Figure 5. (a) HPLC chromatogram showing the retention times and wavelength of MAAs (palythinol and mycosporine-2-glycine) in Calothrix sp. BI22. (b1) Absorption spectrum showing the maximum absorbance for MAA palythinol (as purified by HPLC), at $332 \mathrm{~nm}$ and retention time 3.32 min. (b2) Absorption spectrum showing the maximum absorbance for MAA mycosporine-2-glycine, (as purified by HPLC), at $332 \mathrm{~nm}$ and its retention time was $10.08 \mathrm{~min}$.

\subsection{Lipid Peroxidation}

The level of lipid membrane damage measured as TBARS was not significantly affected by UV-B exposure in $\mathrm{Ca}$ lothrix sp. BI22 (Table 1). Only after 3 hours of exposure, the level of damage became significantly different from the control values in Anabaena sp. BI42 (Table 1).

\subsection{Proline Content}

Quantification of proline showed that after 3 hours of exposure its accumulation became significantly different to control samples of Anabaena sp. BI42. However, proline content showed no significant difference during the experiments in Calothrix sp. BI22 (Table 1).

\subsection{Antioxidant Enzymatic Activities}

Both strains had changes in their antioxidant enzymes activities in response to UV-B exposure (Figure 6). SOD activity showed an opposite trend between the cyanobacterial strains; a significant decrease in Anabaena sp. BI42 and a significant increase in the enzymatic activity in Calothrix sp. BI22 after 3 hours of exposure to UV-B. On the other hand, in Anabaena BI42 and Calothrix sp. BI22, their catalase activity significantly increased after one hour of exposure and dropped down its activity after 3 hours of irradiation. There was no significant change in the APX activity in both strains (Figure 6).

Assays on SOD activity by non-denaturing PAGE gels showed that Anabaena sp. BI42 had two isoforms and Calothrix sp. BI22 one. There was no induction of any new isoform of this enzyme during the exposure to UV-B radiation (Figures 6(c) and (d)). The pre-incubation with inhibitors such as $\mathrm{KCN}$ and $\mathrm{H}_{2} \mathrm{O}_{2}$ showed that both strains have a Fe-dependent SOD isoform (data not shown) (Figure 7).

\section{Discussion}

Cyanobacteria harvest light energy during the process of photosynthesis and assimilate it into carbon compounds. Any adverse effect of UVB may severely affect photosynthesis and related metabolic processes and overall growth performance of cyanobacteria. Although the survival of both cyanobacteria isolates tested decreased after exposure to UV-B irradiation, the responses were different. Previous reports stated that the differences could in part be explained on the basis of antioxidant defenses and DNA repair mechanisms present in each microorganism or simpler ones as morphological features such as presence of sheath $[27,28]$. For instance, Calothrix sp. BI22 has a muscilaginous sheath (data not shown) observed by optic microscopy whereas Anabaena sp. BI42 lacks it. It must be considered that in this work the UV lamp used provided almost exclusively UV-B light and PAR was not applied simultaneously during the irradiation period. Field conditions are quite different and so these results must not be extrapolated. For example, DNA-repair mechanisms included photoreactivation by photolyase after absorption of light energy at $400 \mathrm{~nm}$ or long wavelength UV-A [4].

The laboratory studies presented here show that both photosynthesis and nitrogen fixation in Anabaena sp. BI42 are affected by short exposure times to UV-B, while in Calothrix sp. BI22 only photosynthesis decreased. 
Table 1. Effect of different times of exposure to UV-B on nitrogenasa activity, proline content and lipid peroxidation in Anabaena sp.BI42 and Calothrix sp.BI22.

\begin{tabular}{|c|c|c|c|c|c|c|}
\hline \multirow{2}{*}{$\begin{array}{c}\text { UV-B } \\
\text { treatment (h) }\end{array}$} & \multicolumn{2}{|c|}{$\begin{array}{c}\text { Nitrogenase activity } \\
\left(\mu \mathrm{mol} \mathrm{C}_{2} \mathrm{H}_{4} \mathrm{mg}^{-1} \cdot \mathrm{DW} \cdot \mathrm{h}^{-1}\right)\end{array}$} & \multicolumn{2}{|c|}{$\begin{array}{c}\text { Proline content } \\
\left(\mathrm{nmol} \cdot \mathrm{mL}^{-1} \cdot \mathrm{mg} \cdot \mathrm{DW}^{-1}\right)\end{array}$} & \multicolumn{2}{|c|}{$\begin{array}{c}\text { TBARS } \\
\left(\mathbf{n m o l} \cdot \mathrm{g} \cdot \mathbf{D W}^{-1}\right)\end{array}$} \\
\hline & Anabaena sp. BI42 & Calothrix sp. BI22 & Anabaena sp. BI42 & Calothrix sp. BI22 & Anabaena sp. BI42 & Calothrix sp. BI22 \\
\hline $\mathbf{0}$ & $0.69 \pm 0.18^{\mathrm{a}}$ & $0.18 \pm 0.04^{\mathrm{b}}$ & $1.80 \pm 0.34^{\mathrm{a}}$ & $1.1 .67 \pm 0.55^{\mathrm{a}}$ & $29.5 \pm 14.2^{\mathrm{a}}$ & $6.7 \pm 3.2^{\mathrm{a}}$ \\
\hline 1 & $0.31 \pm 0.05^{\mathrm{b}}$ & $0.39 \pm 0.20^{\mathrm{b}}$ & $2.07 \pm 0.43^{\mathrm{a}}$ & $1.57 \pm 0.65^{\mathrm{a}}$ & $20.6 \pm 8.5^{\mathrm{a}}$ & $7.5 \pm 2.5^{\mathrm{a}}$ \\
\hline 3 & $0.02 \pm 0.01^{\mathrm{c}}$ & $0.28 \pm 0.02^{\mathrm{b}}$ & $3.04 \pm 0.30^{\mathrm{a}}$ & $1.64 \pm 0.05^{\mathrm{a}}$ & $60.0 \pm 4.0^{\mathrm{b}}$ & $6.1 \pm 1.6^{\mathrm{a}}$ \\
\hline
\end{tabular}

Values (means \pm standard deviation) followed by different letters were significantly different at $\mathrm{p}<0.01$.

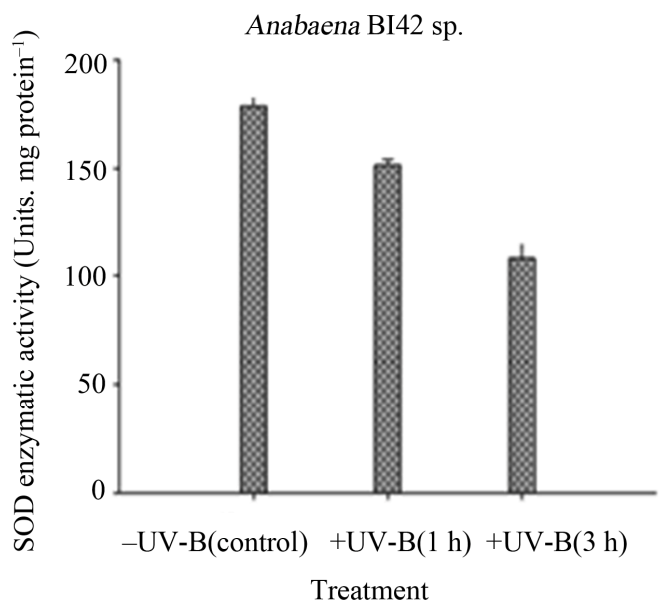

(a)

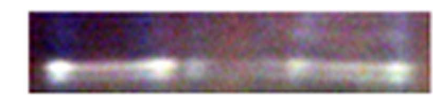

-UV-B(control) +UV-B(1 h) +UV-B(3 h)

(c)

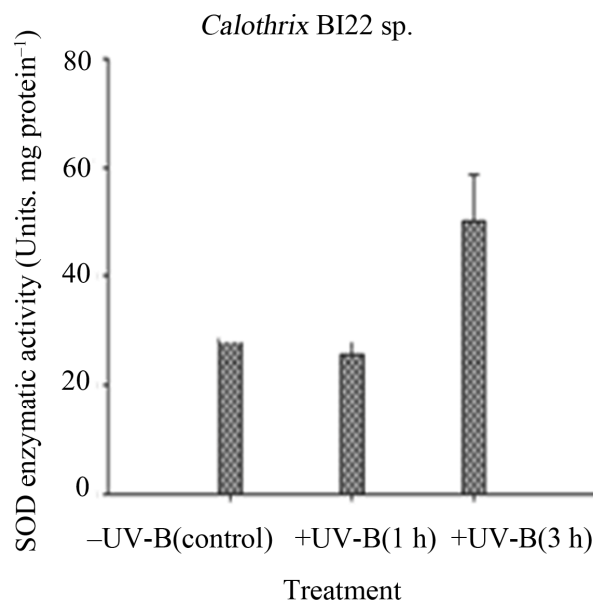

(b)

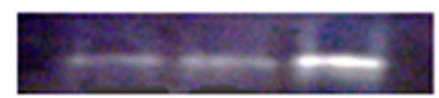

$-\mathrm{UV}-\mathrm{B}($ control) $+\mathrm{UV}-\mathrm{B}(1 \mathrm{~h}) \quad+\mathrm{UV}-\mathrm{B}(3 \mathrm{~h})$

(d)

Figure 6. Superoxide dismutase (SOD) in vitro activities in Anabaena sp. BI42 (a) and Calothrix sp. BI22 (b) after different times of exposure to UV-B. Results are reported as mean of three replicates \pm standard error. Identification of SOD in-gel activities in Anabaena sp. BI42 (c) and Calothrix sp. BI22 (d) for the control and cells irradiated with UV-B for 1 and 3 h.
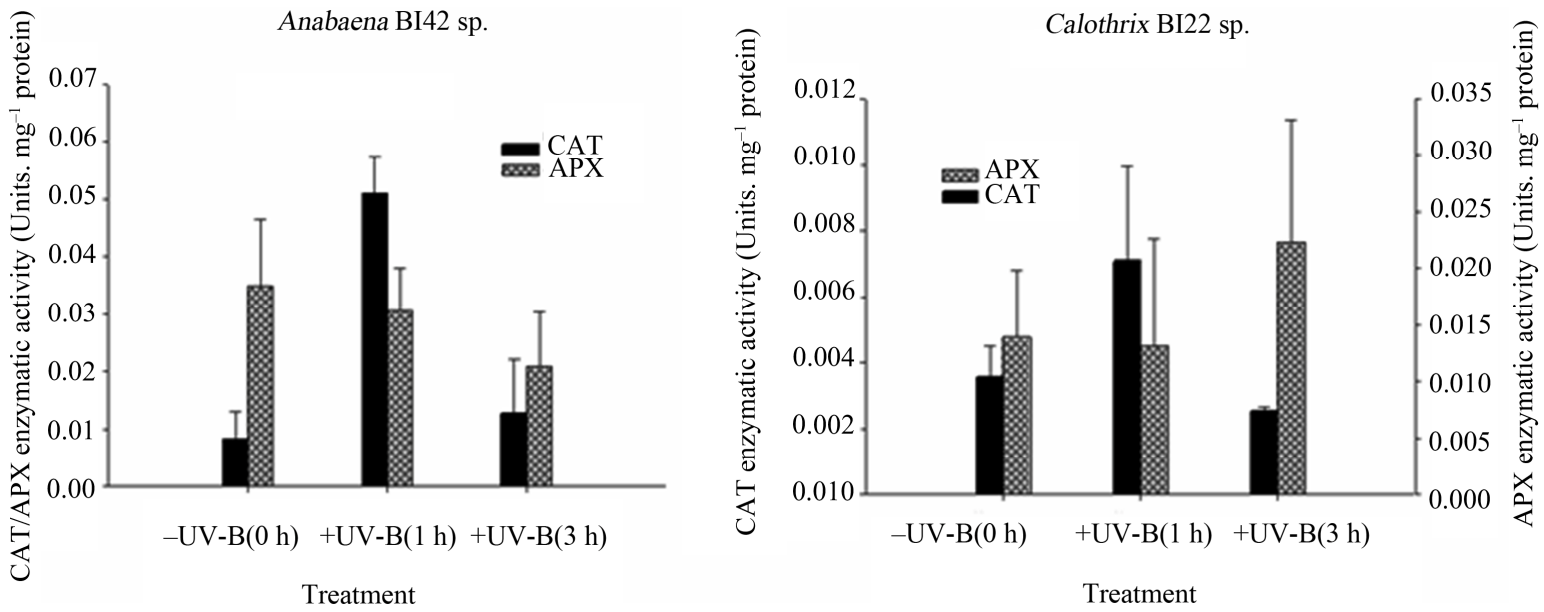

Figure 7. APX and CAT activities in Anabaena sp. BI42 (a) and Calothrix sp. BI22 (b) exposed to UV-B for 0, 1 and 3 h. Results are reported as mean of three replicates \pm standard error. 


\subsection{Pigmentation and Photosynthesis}

Several studies as this one suggest that phycobiliproteins, chlorophyll and carotenoids are negatively influenced by UV-B radiation [29].

The increase in fluorescence emission peaks with the UV-B treatments (Figure 3) was not accompanied by a shift of the peak to shorter wavelengths as has been reported for larger exposure to UV-B [12]. However, the observed slight decay in fluorescence intensity was probably due to less efficiency in light capture in UV-B irradiated cells and loss in efectivity of energy transfer to the photosynthetic reaction center.

Photosynthetic oxygen production declined with artificial UV-B radiation in both isolates investigated. It could be possible that structural changes within the photosynthetic apparatus were induced by short exposure times which affected the energy transfer within the antenna complex. Photosynthesis was more affected in Calothrix sp. BI22, as showed by the fluorescence spectra and $\mathrm{O}_{2}$ photoevolution. Photosynthetic quantum yield that was determined by pulse amplitude-modulated fluorometry can provide information on both photosynthesis and overall acclimation status [30]. Quantum yields of PSII fluorescence showed a decline upon UV-B exposure in $\mathrm{Ca}$ lothrix sp. BI22 (Figure 4). This is consistent with previous studies [31] where accumulation of un-repaired damage over time in cultures exposed to UVR is suggested. A possible explanation is that essential proteins of the PSII like D1 are damaged during exposure [32-34] and probably this explains what was observed in Anabaena sp. BI42. Phycobiliproteins fluorescence may also be contributing to photosynthetic quantum yield as both cyanobacteria possessed different phycobiliproteins [30].

\subsection{Nitrogen Fixation}

The results of nitrogenase activity (Table 1) showed that in Anabaena sp. BI42 this process was drastically inhibited after 3 hours of exposure (near 100\%). This is in accordance to previous studies on other strains of Anabaena sp., but using higher doses of UV-B [29,35] (Newton et al., 1979, Lesser, 2008). In Calothrix sp. BI22, the $\mathrm{N}_{2}$ fixing activity was not affected by UV-B exposure in any treatment. Nitrogen fixation requires ATP and reductant for its activity that come from photosynthesis. Even though photosynthesis $\left(\mathrm{Fv} / \mathrm{Fm}\right.$ and $\mathrm{O}_{2}$ photoevolution) was altered in Calothrix sp. BI22, there is evidence that cyanobacteria contain sufficient endogenous content of reductant and ATP to support the nitrogenase activity [36]. However, [37] showed that nitrogenase inactivation by UV-B is caused by direct damage to nitrogenase polypeptide. They also proved that restoration of the activity depends on de novo synthesis of the enzyme rather than the cellular content of ATP and reductant.

\subsection{Mycosporine Like Aminoacids}

Synthesis of UV-absorbing compounds, such as mycosporine amino acids (MAAs), is an important mechanism preventing UV photodamage. The degree of protection by MAAs depends on the type of aminoacid, location (cytoplasm or extracellular glycan) and species [38]. Calothrix sp. BI42 had two types of MAAs, palythynol $(88 \%)$ and mycosporine-2-glycine (12\%). The same kind of MAAs had been found in Nostoc punctiforme in colonies exposed to high solar radiation [39]. MAA-Gly is reported to be located in the extracellular glycan [40]; [41]. Apart from the benefits from being in the outer membrane, MAA-Gly is reported to give additional protection because it can act as a radical quencher [42]. The experimental conditions used in this study did not induce any increase or variation in Calothrix's MAAs content. In other studies MAAs synthesis was also influenced by the irradiation conditions [26] and higher doses or longer times of irradiation increased MAAs content [31]. A constituve level of MAAs can appear in all growth conditions of cyanobacteria as observed in Calothrix sp. BI42. This cyanobacterium grows in aggregates which is said to substantially increase the screening efficiency of MAAs [43]. Anabaena sp. BI22 did not show the presence of any MAAs nor any induction of them with exposure to the UV-B doses assayed. Other surveys reported that from 22 cyanobacterial isolates, only 13 were found to contain MAAs [44]. However, [16] found in an Anabaena sp. isolated from an Indian rice paddy-field the presence of shinorine. None of the strains tested showed the presence of scytonemin (data not shown) which is said to be induced by UV-A irradiation and other type of stresses [45].

\subsection{Antioxidant Potential}

Anabaena sp. BI42, after 3 hours of exposure showed a significant increase of lipid membrane damage measured as TBARS (Table 1). This provides indirect evidence of increased photoxidative damage stress by ROS after UV-B exposure in this cyanobacterium as has been reported before $[27,46]$. There was no significant change in lipid peroxidation in Calothrix sp. BI22.

Proline is an iminoacid essential to primary metabolism whose accumulation has been related to unfavourable conditions in plants [47] and cyanobacteria [48,49]. According to [50] intracellular proline detoxifies harmful ROS directly rather than improving key antioxidant enzymes. Our results are in accordance with this, because Anabaena showed an increase in TBARS and in proline content after 3 hours of exposure. No effect in the proline content was seen in Calothrix sp. BI22 (Table 1).

During oxidative stress ROS triggered the activity of several antioxidative enzymes such as SOD (EC 1.15.1.1), 
CAT (EC 1.11.1.6), and APX (EC 1.11.1.11). High activity of these enzymes in cyanobacteria could be linked to stress tolerance efficiency [46].

As has been stated by [51], cyanobacteria can have iron-containing SOD (cytosolic) and manganese-containing SOD (thylacoid-bound) isoforms. The strains tested have both a Fe-SOD isoform and no other isoform was induced due to the experimental conditions (Figures 6(c) and (d)). SOD activities have been shown to change dramatically in response to conditions that favour the formation of superoxide [52]. Calothrix sp. BI22 showed a significant increase of its activity after the maximum exposure time (Figure 6(b)). [53] reported that $\mathrm{O}_{2}^{-}$is the first ROS generated as a consequence of UV-B stress. Like in other studies [54,55], the result obtained supports the fact that SOD plays an important role in protecting Calothrix sp. BI42 from UV-B stress. However, Anabaena sp. BI42 showed a decrease in the same conditions (Figure 5(a)). It has also been reported that only UV-B produced the decrease of SOD activity in microalgae $[56,57]$ found that in plants SOD activity can increase or diminish according to the species, UV-B dose and the presence or not of concomitant PAR or UVA radiation.

CAT activity had a significant increase in both strains after one hour of exposure to UV-B (Figures 7(a) and (b)). After 3 hours of irradiation, levels of CAT activity fell down reaching the values observed in the Control treatment in both strains. This result has been reported before $[54,58]$ and inactivation of CAT due to UV-B is as consequence of photoinactivation and degradation [59] of the haem group in CAT. According to [60], UV-B inhibition of CAT could be a survival strategy in order to prevent accumulation of $\mathrm{H}_{2} \mathrm{O}_{2}$ in the cell.

UV-B irradiation did not significantly affect the APX activity in both strains (Figures 7(a) and (b)). It seems probable that in this moderate UV-B irradiation study, APX is not involved in the protective mechanisms against it in both cyanobacterial strains.

Many effects reported in the literature indicate species-specific responses to UVR. In this case, the two strains studied under laboratory conditions had different potential survival rates that can be partially explained by the synthesis of UV absorbing compounds and their antioxidant potential.

\section{Conclusions}

Two cyanobacteria strains isolated from the same rice field had different responses to UV-B irradiation doses comparable to the natural solar UV radiation reaching Uruguay's latitude during rice growing season. Both photosynthesis and nitrogen fixation were affected by moderate UV-B radiation in the Anabaena isolate. $\mathrm{Ca}$ lothrix sp. BI22 seems to have a better and wide suite of protective mechanisms which include constitutive adap- tations like presence of a sheath or MAAs. It also showed a better antioxidant response to UV-B which may be involved in the successful scavenging of ROS and protecttion of physiological processes of this cyanobacterium.

All in all these results indicate that Calothrix sp. BI22 may be a better candidate than Anabaena sp. BI42 to be used as an inoculant in Uruguayan rice paddy fields when considering UV-B thriving strategies.

\section{Acknowledgements}

Financial assistance was from Consejo Sectorial de Investigación Científica (CSIC-Universidad de la República). We thank Dr. D.-P. Häder for sending us his papers and providing MAAs standards and Dr. J. Monza and P. Díaz for their suggestions.

\section{REFERENCES}

[1] V. L. Orce, A. Paladini and E. W. Helbling, "Radiación Ultravioleta y Ozono Atmosférico: Influencia del Agujero de Ozono en Argentina," In: G. R. Forno and F. M. Andrade, Eds., Naturaleza y Efectos de la Radiación Ultravioleta y la Capa de Ozono, Instituto de Investigaciones Físicas-UMSA, La Paz, 1997, pp. 31-41.

[2] Y.-Y. He, M. Klisch and D.-P. Häder, "Adaptation of Cyanobacteria to UV-B Stress Correlated with Oxidative Stress and Oxidative Damage," Photochemistry and Photobiology, Vol. 76, No. 2, 2002, pp. 188-196.

[3] D.-P. Häder, H. D. Kumar, R. C. Smith and R. C. Worrest, "Effects of Solar UV Radiation on Aquatic Ecosystems and Interactions with Climate Change," Photochemical \& Photobiological Sciences, Vol. 10, No. 3, 2007, pp. 267285.

[4] R. P. Sinha and D.-P. Häder, "UV-Protectants in Cyanobacteria," Plant Science, Vol. 174, No. 3, 2008, pp. 278289. doi:10.1016/j.plantsci.2007.12.004

[5] A.Vaishampayan, R. P. Sinha, D.-P. Häder, T. Dey, A. K. Gupta, U. Bhan and A. L. Rao, "Cyanobacterial Biofertilizers in Rice Agriculture," Botanical Review, Vol. 67, No. 4, 2001, pp. 453-516. doi:10.1007/BF02857893

[6] P. Irisarri, "Role of Cyanobacteria as Biofertilizers: Potentials and Limitations," In: M. K. Rai, Ed., Handbook of Microbial Fertilizers, The Haworth Press Inc., Binghamton, 2006. pp. 417-430.

[7] P. Irisarri, S. Gonnet, E. Deambrosi and J. Monza, "Cyanobacterial Inoculation and Nitrogen Fertilization in Rice," World Journal of Microbiology and Biotechnolology, Vol. 23, No. 2, 2007, pp. 237-242. doi:10.1007/s11274-006-9219-0

[8] L. Aubriot, D. Conde, S. Bonilla and R. Sommaruga, "Phosphate Uptake Behavior of Natural Phytoplankton during Exposure to Solar Ultraviolet Radiation in a Shallow Coastal Lagoon," Marine Biology, Vol. 144, No. 4, 2004, pp. 623-631. doi:10.1007/s00227-003-1229-y

[9] T. D. B. MacKenzie, R. A. Burns and D. Campbell, "Carbon Status Constrains Light Acclimation in the Cyanobacterium Synechococcus elongatus," Plant Physiology, Vol. 
136, No. 2, 2004, pp. 3301-3312. doi:10.1104/pp.104.047936

[10] P. Irisarri, S. Gonnet, E. Deambrosi and J. Monza, "Diversidad de Cyanobacterias con Heterocisto en Suelos Cultivados con Arroz," Agrociencia, Vol. 1, No. 3, 1999, pp. 44-49.

[11] R. Rippka, J. Deruelles, J. B. Watterbury, M. Herdman and R. Y. Stainer, "Generic Assignments, Strain Histories and Properties of Pure Cultures of Cyanobacteria," Journal of General Microbiology, Vol. 111, No. 1, 1979, pp. $1-61$.

[12] V. A. Donkor and D.-P. Häder, "Effects of Ultraviolet Irradiation on Photosynthetic Pigments in Some Filamentous Cyanobacteria," Aquatic Microbial Ecology, Vol. 11, No. 2, 1996, pp. 143-149. doi:10.3354/ame011143

[13] A. Benett and L. Bogorad, "Complementary Chromatic Adaptation in a Filamentous Blue-Green Alga," Journal of Cell Biology, Vol. 58, No. 2, 1973, pp. 419-435. doi:10.1083/jcb.58.2.419

[14] D.-P. Häder, M. Lebert, R. Marangoni and G. Colombetti, "ELDONET-European Light Dosimeter Network Hardware and Software," Journal of Photochemistry and Photobiology B: Biology, Vol. 52, No. 1-3, 1999, pp. 51-58. doi:10.1016/S1011-1344(99)00102-5

[15] K. Roháček and M. Barták, "Technique of the Modulated Chlorophyll Fluorescence: Basic Concepts, Useful Parameters, and Some Applications," Photosynthetica, Vol. 37, No. 3, 1999, pp. 339-363. doi:10.1023/A:1007172424619

[16] R. P. Sinha, M. Klisch, A. Vaishampayan and D.-P. Häder, "Biochemical and Spectroscopic Characterization of the Cyanobacterium Lyngbya sp. Inhabiting Mango (Mangifera indica) Trees: Presence of an Ultraviolet-Absorbing Pigment, Scytonemin," Acta Protozoologica, Vol. 38, No. 4, 1999, pp. 291-298.

[17] G. Minotti and S. Aust, "The Requirement for Iron (III) in the Initiation of Lipid Peroxidation by Iron (II) and Hydrogen Peroxide," Journal of Biological Chemistry, Vol. 262, No. 3, 1987, pp. 1098-1104.

[18] C. Rusterucci, V. Stallaert, M. Milat, A. Pugin, P. Ricci and J. Blein, "Relationship between Active Oxygen Species, Lipid Peroxidation, Necrosis, and Phytoalexin Production Induced by Elicitins in Nicotiana," Plant Physiology, Vol. 111, No. 3, 1996, pp. 885-891.

[19] O. Borsani, P. Díaz and J. Monza, "Proline is Involved in Water Stress Responses of Lotus corniculatus Nitrogen Fixing and Nitrate Fed Plants," Journal of Plant Physiology, Vol. 155, No. 2, 1999, pp. 269-273. doi:10.1016/S0176-1617(99)80018-2

[20] J. G. Foster and J. L. Hess, "Responses of Superoxide Dismutase and Glutathione Reductase Activities in Cotton Leaf Tissue Exposed to an Atmosphere Enriched in Oxygen1," Plant Physiology, Vol. 66, No. 3, 1980, pp. 482487. doi:10.1104/pp.66.3.482

[21] R. F. Beer and I. W. Sizer, "A Spectrophotometric Method for Measuring the Breakdown of Hydrogen Peroxide by Catalase," Journal of Biological Chemistry, Vol. 195, 1952, pp. 133-140.

[22] G.-X. Chen and K. Asada, "Ascorbate Peroxidase in Tea Leaves: Occurrence of Two Isozymes and the Differences in Their Enzymatic and Molecular Properties," Plant Cell Physiology, Vol. 30, No. 7, 1989, pp. 987-998.

[23] O. H. Lowry, N. J. Rosenbrough, A. L. Farr and R. J. Randall, "Protein Measurement with the Folin Phenol Reagent," Journal of Biological Chemistry, Vol. 193, 1951, pp. 265-275.

[24] J. L. Donahue, C. M. Okpodu, C. L. Cramer, E. A. Grabau and R. G. Alscher, "Responses of Antioxidants to Paraquat in Pea Leaves (Relationships to Resistance)," Plant Physiology, Vol. 113, No. 1, 1997, pp. 249-257.

[25] M. Sainz, P. Díaz, J. Monza and O. Borsani, "Heat Stress Results in Loss of Chloroplast $\mathrm{Cu} / \mathrm{Zn}$ Superoxide Dismutase and Increased Damage to Photosystem II in Combined Drought-Heat Stressed Lotus japonicus," Physiologia Plantarum, Vol. 140, No. 1, 2010, pp. 46-56. doi:10.1111/j.1399-3054.2010.01383.x

[26] R. P. Sinha, M. Klisch, A. Gröniger and D.-P. Häder, "U1traviolet Absorbing/Screening Substances in Cyanobacteria, Phytoplankton and Macroalgae," Journal of Photochemistry \& Photobiology B: Biology, Vol. 47, No. 2-3, 1998, pp. 83-94. doi:10.1016/S1011-1344(98)00198-5

[27] Y. Y. He and D.-P. Häder, "UV-B Induced Formation of Reactive Oxygen Species and Oxidative Damage of the Ascorbic Acid and N-Acetyl.L-Cysteine," Photochemical \& Photobiological Sciences, Vol. 1, No. 10, 2002, pp. 729736. doi: $10.1039 / \mathrm{b} 110365 \mathrm{~m}$

[28] P. S. Singh, R. P. Sinha, M. Klisch and D.-P. Häder, "Mycosporine-Like Amino Acids (MAAs) Profile of a Rice-Weld Cyanobacterium Anabaena doliolum as Influenced by PAR and UVR," Planta, Vol. 229, No. 1, 2008, pp. 225-233. doi:10.1007/s00425-008-0822-1

[29] M. P. Lesser, "Effects of Ultraviolet Radiation on Productivity and Nitrogen Fixation in the Cyanobacterium, Anabaena sp. (Newton's Strain)," Hydrobiologia, Vol. 598, No. 1, 2008, pp. 1-9. doi:10.1007/s10750-007-9126-x

[30] D. Campbell, V. Hurry, A. K. Clarke, P. Gustaffson and G. Öquist, "Chlorophyll Fluorescence Analysis of Cyanobacterial Photosynthesis and Acclimation," Microbiology \& Molecular Biology Review, Vol. 62, No. 3, 1998, pp. 667-683.

[31] M. Lesser, "Oxidative Stress in Marine Environments: Biochemistry and Physiological Ecology," Annual Review of Physiology, Vol. 68, 2006, pp. 253-278. doi:10.1146/annurev.physiol.68.040104.110001

[32] M. Lesser, J. Neale and J. J. Cullen, "Acclimation of Antartic Phytoplankton to Ultraviolet Radiation: Ultraviolet-Absorbing Compounds and Carbon Fixation," Molecular Marine Biology Technology, Vol. 5, No. 4, 1996, pp. 314-332.

[33] C. Hazzard, M. P. Lesser and R. A. Kinzie III, "Effects of Ultraviolet Radiation on Photosynthesis in the Subtropical Marine Diatom, Chaetoceros gracilis (Baccilariophyceae)," Journal of Phycology, Vol. 33, No. 6, 1997, pp. 960-968. doi:10.1111/j.0022-3646.1997.00960.x

[34] J. N. Bouchard, D. A. Roy and D. A. Campbell, "UVB Effects on the Photosystem II-D1 Protein of Phytoplankton and Natural Phytoplankton Communities," Photochemistry \& Photobiology, Vol. 82, No. 4, 2006, pp. 936 - 


\section{1. doi:10.1562/2005-08-31-IR-666}

[35] J. W. Newton, D. D. Tyler and M. E. Slodki, "Effects of Ultraviolet-B (290-320 nm) Radiation on Blue-Green Algaea (cyanobacteria), Possible Biological Indicators of Straspheric Ozone Depletion," Applied and Environmental Microbiology, Vol. 37, No. 6, 1979, pp. 1137-1141.

[36] W. D. P. Stewart, "Some Aspects of Structure and Function in N Fixing Cyanobacteria," Annual Review of Microbiology, Vol. 34, 1980, pp. 497-536. doi:10.1146/annurev.mi.34.100180.002433

[37] A. Kumar, M. Tyagi, P. B. Jha, G. Srinivas and A. Singh, "Inactivation of Cyanobacterial Nitrogenase after Exposure to Ultraviolet-B Radiation," Current Microbiology, Vol. 46, No. 5, 2003, pp. 380-384. doi:10.1007/s00284-001-3894-8

[38] M. Ehling-Schulz and S. Scherer, "UV Protection in Cyanobacteria," European Journal of Phycology, Vol. 34, No. 4, 1999, pp. 329-338. doi:10.1080/09670269910001736392

[39] S. Scherer, H. Riege and P. Böger, "Light-Induced Proton Release by the Cyanobacterium Anabaena variabilis: Dependence on Carbon Dioxide and Sodium," Plant Physiology, Vol. 86, No. 3, 1988, pp. 769-772. doi:10.1104/pp.86.3.769

[40] D. R. Hill, S. L. Hladun, S. Scherer and M. Potts, "Water Stress Proteins of Nostoc commune (Cyanobacteria) are Secreted with UV-A/B-absorbing Pigments and Associate with 1,4-b-D-Xylanxylanohydrolase Activity," Journal of Biological Chemistry, Vol. 269, No. 10, 1994, pp. 77267734.

[41] G. A. Böhm, W. Pfleiderer, P. Böger and S. Scherer, "Structure of a Novel Oligosaccharide-Mycosporine-Amino Acid Ultraviolet A/B Sunscreen Pigment from the Terrestrial Cyanobacterium Nostoc commune," Journal of Biological Chemistry, Vol. 270, 1995, pp. 8536-8539. doi:10.1074/jbc.270.15.8536

[42] W. C. Dunlap and Y. Yamamoto, "Small-Molecule Antioxidants in Marine Organisms: Antioxidant Activity of Mycosporine-Glycine," Comparative Biochemistry and Physiology Part B: Biochemistry and Molecular Biology, Vol. 112, No. 1, 1995, pp. 105-114. doi:10.1016/0305-0491(95)00086-N

[43] R. W. Castenholz, "Multiple Strategies for UV Tolerance in Cyanobacteria," Spectrum, Vol. 10, 1997, pp. 10-16.

[44] F. Garcia-Pichel and R. W. Castenholz, "Occurrence of UV-Absorbing, Mycosporine-Like Compounds among Cyanobacterial Isolates and an Estimate of Their Screening Capacity," Applied and Environmental Microbiology, Vol. 59, No. 1, 1993, pp. 163-169.

[45] J. G. Dillon, M. C. Tatsumi, P. G. Tandingan and R. W. Castenholz, "Effect of Environmental Factors on the Synthesis of Scytonemin, a UV Screening Pigment, in Cyanobacteria (Chroococcidiopsis sp.)," Archives of Microbiology, Vol. 177, No. 4, 2002, pp. 322-331. doi:10.1007/s00203-001-0395-x

[46] M. Zeeshan and S. M. Prasad, "Differential Response of Growth, Photosynthesis, Antioxidant Enzymes and Lipid Peroxidation to UV-B Radiation in Three Cyanobacteria," South African Journal of Botany, Vol. 75, No. 3, 2009, pp. 466-474. doi:10.1016/j.sajb.2009.03.003
[47] L. Szabados and A. Savouré, "Proline: A Multifunctional Amino Acid," Trends in Plant Science, Vol. 15, No. 2, 2009, pp. 89-97.

[48] A. K. Singh, D. Chakravarty, T. P. K. Singh and H. N. Singh, "Evidence for a Role of L-Proline as a Salinity Protectant in the Cyanobacterium Nostoc muscorum," Plant Cell Environment, Vol. 19, No. 4, 1996, pp. 490-494. doi:10.1111/j.1365-3040.1996.tb00342.x

[49] A. Chris, M. Zeeshan, G. Abraham and S. M. Prasad, "Proline Accumulation in Cylindrospermum sp.," Environmental \& Experimental Botany, Vol. 57, No. 1-2, 2006, pp.154-159. doi:10.1016/j.envexpbot.2005.05.008

[50] B. N. Tripathi and J. P. Gaur, "Relationship between Copper- and Zinc-Induced Oxidative Stress and Proline Accumulation in Scenedesmus sp.," Planta, Vol. 219, No. 3, 2004, pp. 397-404. doi:10.1007/s00425-004-1237-2

[51] K. Asada, "Superoxide Dismutase," In: S. Otsuka and T. Yamanaka, Eds., Metalloproteins, Elsevier, Amsterdam, 1988, pp. 331-341.

[52] C. Obinger, C. Günther, M. Regelsberger, A. Pircher, G. Strasser and G. Pescheck, "Scavenging of Superoxide and Hydrogen Peroxide in Blue-Green Algae (Cyanobacteria)," Physiologia Plantarum, Vol. 104, No. 4, 1998, pp. 693-698. doi:10.1034/j.1399-3054.1998.1040425.x

[53] S. Mackerness, C. F. John, B. R. Jordan and B. Thomas, "Early Signaling Components in Ultraviolet-B Responses: Distinct Roles for Different Reactive Oxygen Species and Nitric Oxide," FEBS Letters, Vol. 489, No. 2, 2001, pp. 237-242. doi:10.1016/S0014-5793(01)02103-2

[54] P. Bhargava, N. Atri, A. K. Srivastava and L. C. Rai, "Cadmium Mitigates Ultraviolet-B Stress in Anabaena doliolum: Enzymatic and Non-Enzymatic Antioxidants," Biologia Plantarum, Vol. 51, No. 3, 2007, pp. 546-550. doi:10.1007/s10535-007-0118-5

[55] B. Shirkey, D. P. Kovarcik, D. J. Wright, G. Wilmoth, T. F. Prickett, R. F. Helm, E. M. Gregory and M. Potts, "Active Fe-Containing Superoxide Dismutase and Abundant sodF mRNA in Nostoc commune (Cyanobacteria) after Years of Desiccation," Journal of Bacteriology, Vol. 182, No. 1, 2000, pp. 189-197. doi:10.1128/JB.182.1.189-197.2000

[56] X. F. Zhang, F. X. Kong, H. S. Cao, J. K. Tan, Y. Tao and M. L Wang, "Research on Recruitment Dynamics of Bloom-Forming Cyanobacteria in Meiliang Bay, Taihu Lake," Chinese Journal of Applied Ecology, Vol. 16, No. 7, 2005, 1346-1350.

[57] J. Dat, S. Vandenabeele, E.Vranová, M. Van Montagu, D. Inzé and F. Van Breusegem, "Dual Action of the Active Oxygen Species during Plant Stress Responses," Cellular Molecular Life Sciences, Vol. 57, No. 5, 2000, pp. 779795. doi:10.1007/s000180050041

[58] R. Aráoz and D.-P. Häder, "Phycoerythrin Synthesis is Induced by Solar UV-B in the Cyanobacterium Nostoc," Plant Physiology and Biochemistry, Vol. 37, No. 3, 1999, pp. 223-229. doi:10.1016/S0981-9428(99)80037-0

[59] P. Streb, A. Michael-Knauf and J. Feierabend, "Preferential Photoinactivation of Catalase and Photoinhibition of Photosystem II Are Common Early Symptoms under Various Osmotic and Chemical Stress Conditions," Physi- 
ologia Plantarum, Vol. 88, No. 4, 1993, pp. 590-598. doi:10.1111/j.1399-3054.1993.tb01376.X

[60] M. Wirstam, M. R. A. Blomberg and P. E. M. Siegbahn, "Reaction Mechanism of Compound I Formation in Heme
Peroxidases: A Density Functional Theory Study," Journal of American Chemistry Society, Vol. 121, No. 43, 1999, pp. 10178-10185. doi:10.1021/ja991997c 